\title{
Disaster Management Through Digital Platforms: Online Crowdfunding Communities Respond to the COVID-19 Pandemic
}

\author{
Anqi (Angie) Wu, Aravinda Garimella, Ramanath Subramanyam, Mehmet Ahsen* \\ University of Illinois at Urbana-Champaign \\ \{anqiwu2, aravinda,rsubrama\}@illinois.edu \\ * The authors contributed equally to this work.
}

\begin{abstract}
We study how digital crowdfunding platforms can help replenish the sudden economic deficiencies that accompany a global crisis. Specifically, we examine whether public schools, which suffered severe setbacks during the COVID-19 crisis, were able to generate support from online fundraising communities. We study how the shutdown of schools and the shift to online learning in the United States affected private fundraising on the DonorsChoose.org platform. We find evidence that, after the exogenous shock caused by stay-at-home orders, donations to schools increased and the increased level of concern moves toward high-need schools. Moreover, we find a shift in donation patterns, wherein donors swiftly adapted to renewed priorities and redistributed their resources to immediate needs around digital learning infrastructure. Our findings reveal the pivotal role digital platforms can play in facilitating community resilience during times of crisis.
\end{abstract}

\section{Introduction}

As the world begins to take stock of and address the consequences of the COVID-19 pandemic, it is now clear that the pandemic changed children's lives in profound ways. According to UNICEF, at least a third of the world's schoolchildren - 463 million children globally - could not access remote learning when COVID-19 shuttered their schools ${ }^{1}$. In the United States, many regions decided to close educational institutions until plans were put in place to restart in a controlled manner, with flexibility given to schools to choose offline and/or online program implementations. With many students expected to do online learning at home this fall, the pandemic amplified the existing digital divide between families with reliable internet access and devices, such as computers, and those who do not [1]. This sudden transition compelled teachers

${ }^{1}$ https://data.unicef.org/covid-19-and-children/ last accessed Nov $25,2020$. to equip students for distance learning. Supplies required ranged from books and education kits to games for hands-on learning, in addition to the pre-existing demand for classroom basics like pencils and notebooks.

To address the dire need for federal investments in K-12 education, the U.S. Congress passed the Coronavirus Aid, Relief, and Economic Security (CARES) Act in March 2020. This, a 2 trillion USD economic relief package, included 13.5 billion USD for states and school districts as emergency relief and to stabilize education [2]. However, education advocacy groups have deemed that this relief fell far short of what was needed, putting forward estimates ranging from more than 100 billion USD to about 250 billion USD for the amount needed to stabilize state and local K-12 budgets, close gaps in remote learning, provide students with mental, physical, and academic supports, and provide a safe school environment for educators and students when schools reopen [3]. Policymakers consider the drastic short-term disruptions incurred by families, including the impact on student social life and learning, and the long-term effects on education, schools, and child development as serious concerns. The severe impacts on teachers, students, and learning communities are noted unequivocally. Studies previously established that public schools in the United States of America are both underfunded and inequitably funded. Limited budgets and red tape have periodically led teachers to dip into their own pockets for classroom projects.

More recently, philanthropic crowdfunding, enabled through platforms like DonorsChoose.org or GoFundMe.com, has encouraged teachers to drive decisions about what to raise funds for and how much to raise. In such platforms, money can reach the target audience as soon as funding is complete. A teacher can set up a campaign in a matter of minutes and receive funding for basic classroom supplies, curricular materials, technology, enrichment programs and a host of other expenses. When it works, crowdfunding can provide fast money directly to teachers with few barriers 
to entry. The overall impact of such platforms has been increasing over time. For example, DonorsChoose recently highlighted that more than a billion dollars (USD 1034M) have been raised over the last two decades with funds wholly going towards teacher-led and student-led projects serving school needs ${ }^{2}$.

The role of crowdfunding platforms draws a critical focus on government funding efficacy during the pandemic. While government funding would only gradually trickle down to the schools over time, and be allocated in a centralized manner, teachers who are close to the ground reality know first-hand the immediate needs of their students and can independently request and receive immediate help. However,the effectiveness of these platforms in times of crisis is unclear. The ability of the members of online communities to facilitate resilience may be severely limited by the impact of the pandemic on their own resources due to unprecedented job losses [4] and the shutting down of numerous small businesses [5]. Contrarily, crises can lead to an increased sense of community and inspire its members to come together to rebound from the dire effects of the pandemic.

This paper empirically examines the response of online crowdfunding communities to the COVID-19 pandemic and the ensuing stay-at-home orders issued by states. We specifically examine the DonorsChoose platform to answer two key research questions: (1) Can the community and platform respond to the pandemic by helping fill areas of need? (2) Does the empathic response to the pandemic redistribute private donations? Our empirical analysis starts by examining project funding outcomes and donor behavior before and after the school closures enacted by the policy makers. We collate a weekly panel of data representing more than 54,000 schools and more than 780,000 donors. This data consists of the fundraising outcomes of U.S. public elementary and secondary school teachers as solicitors seeking donations on the DonorsChoose.org platform. We combine this data with information about school demographics and characteristics such as student count and the number of full-time equivalents collected from National Center for Education Statistics (NCES). We find that, during the time window when the pandemic necessitated school closures, there was an observed increase in community-mobilized resources to support public education. We note that institutional donors take a more leading role in fundraising compared to individual donors in driving donations. We observe community empathetic behavior that channelled higher levels of donations to high-need schools and

\footnotetext{
${ }^{2}$ Source: https://www.donorschoose.org/about/impact.html last accessed Nov 20, 2020
}

dynamically adjusted to renewed priorities. Requests for technological provisions like laptops for remote learning were funded at a faster rate than basic classroom needs. Basic classroom necessities continued to receive contributions at the traditional rate. Overall, we find two forms of resilience in the community - that of the community (e.g., donors) rallying around schools and that of the platform which enables the efficient redistribution of resources.

\section{Literature and Hypotheses}

As we examine a multi-faceted phenomenon where a digital market serves as a central mechanism for voluntary philanthropic giving and the myriad decisions recipients and donors make in this setting, we draw from three streams of literature. First, we incorporate the growing body of research in information systems that studies online crowdfunding and charitable donations. $[6,7,8]$. Previous empirical research has explored various factors within the crowdfunding ecosystem that drive the donor behavior or crowdfunding outcomes, such as the characteristics of solicitors [9], access to information controls [10], the social network and activities among advocates [11], and information on prior contribution behavior [12], and charity performance metrics [13]. Our view building on this research is that digital platforms can serve as digital markets for philanthropy, which greatly reduce the costs of search and discovery [14]. Platforms can leverage large volumes of donor and recipient data and a comprehensive data-supported body of knowledge to help withstand or path-correct during periods of external shocks.

The second area that informs our research questions and hypotheses is that of voluntary giving and philanthropy. Since philanthropy is a natural phenomenon where public needs are met and private beliefs and commitments are revealed, the degree of matching that naturally occurs reveals the extent the platform serves for true public good [15]. There are two perspectives prevalent in the voluntary giving and civic engagement literature. The substitution-based view is that voluntary action originates from an unsatisfied demand for collective goods not met by the government [16]. If the government performs these tasks, the engagement of private volunteers in the society is rendered unnecessary and will consequently decrease. In contrast to this view is a complementariness-based view between governmental initiatives and private voluntary action [17]. In this view, governmental effort does not replace civic activities, but remains complementary to civic engagement [18]. 
Our examination of crowdfunding behavior during this period of COVID-19 induced disruption will help us examine whether donors and the platform ecosystem conform to the former or the latter view.

Third, since our research setting encourages both individual and institutional giving explicitly, we draw from the literature on drivers of individual and institutional philanthropy [15]. While most individuals are moved by a mix of expressive and instrumental purposes [15], institutions are often motivated by factors like efficacy, corporate social responsibility (CSR), (frumkin2008strategic), and profits fry1982corporate. The role of the health of the economy has also been noted in literature. Given the critical role of the COVID-19 pandemic and the heterogeneous drivers of participation across individuals and corporations, we explicitly incorporate the role of the source - individual versus corporate entity as a financial driver of resilience.

Drawing from the above streams of literature, we develop hypotheses around community resilience during a pandemic, made possible via digital platforms. Extant literature on prosocial behavior adopts two perspectives on the motivations for prosocial actions. One perspective is that volunteering reflects a person's personality: some people are by their nature helpful, active, and generous, and some people are less so [19]. The other explanation emphasizes the circumstances and posits that "people tend to do things because of where they are, not who they are." In subtly different circumstances, people might behave in radically different ways [16].

From this circumstantial point of view, global crises, whether economic, natural, or political in nature, have profound impacts on human behavior. Disasters and crises deplete resources, break up and isolate communities, and can be appraised as traumatic [20]. Research in terror management suggests that events such as the COVID-19 pandemic can serve as experiential reminders of mortality and invoke feelings of anxiety [21]. Mortality salience around crises encourages people to put life in perspective, overcome obstacles, and provide more help for others [22]. We hypothesize as follows.

Hypothesis la (Hla): The pandemic leads to an overall increase in community - mobilized resources to support public school projects.

Crises such as COVID-19 hurt poor communities disproportionately due to high vulnerability and low ability to cope and recover [23]. Schools in poor neighborhoods that have fewer resources to begin with experienced pandemic-induced shortages to a much larger extent [24]. Periods of crisis could prompt introspection and shift communities towards a complementariness-based view of their role in society. In the complementariness-based view, people and institutions hold that governmental efforts do not replace civic activities, but rather remain complementary to civic engagement [17]. We expect communities to effectively facilitate resilience and channel their efforts towards sections that need it most. In this case, schools serving greater proportions of low socio-economic status (SES) students would be among the most vulnerable. This informs our hypothesis, as follows.

Hypothesis $1 b(H 1 b)$ : The pandemic leads to a higher increase in community - mobilized resources to support projects from public schools catering to low SES students.

While our above hypotheses provide the rationale for collective community behavior during times of need, there is further need to elucidate how donors prioritize contributions in such times. Prior literature on risk and uncertainty suggest that deciding whom to help may be particularly difficult because the emotions evoked during humanitarian crisis are often poorly calibrated with the objective deadliness, severity, or scope of that crisis [25]. People exhibit an immediacy bias when making judgments and decisions about humanitarian aid, perceiving certain facets as more deserving and donating disproportionately to humanitarian crises that happen to arouse immediate emotion [26]. Immediate emotion can also indirectly influence judgments and decisions about humanitarian aid through people's perception that immediate emotions are more intense than previous emotions [27]. The immediacy bias can lead to people allocating disproportionate charitable resources toward immediately evocative humanitarian needs. This interplay of emotion driven donation and the restrictions of the pandemic means some needs of schools are likely to rise in prominence (e.g., access to internet, laptops and tablets) while others are likely to take a back seat (e.g., better classroom seating, musical instruments). We expect the community to adapt swiftly to these renewed priorities, to mobilize, and channel their resources accordingly.

Hypothesis 2 (H2): $\quad$ Communities redistribute their resources during the pandemic, prioritizing high-immediacy needs.

Societal crisis management includes measures taken by individuals and collectives to enhance community resilience. Both individuals and institutions seek a renewed sense of purpose to guide them through uncertainty in times of crisis. We seek to examine the roles of individuals and organizations separately. Both are uniquely positioned and motivated in divergent complementary ways to perform actions that heighten community resilience during a crisis. 
Individual philanthropy can take a hit during times of crisis. Pandemics lead to unprecedented job losses and the shutting down of numerous small businesses. Economic theory suggests that the sudden, largely unanticipated reduction of wealth by an external force will lead to lower disposable income available to allocate toward charity. Contrarily, crises can boost charity by citizens due to an increase in the "community feeling". Systematic empirical studies of the Halifax harbor 1917 munitions ship explosion, social effects of World War II bombing, the 1953 tornadoes at Worcester, Massachusetts and at Waco and San Angelo, Texas, and finally events following the 1961 disaster of Hurricane Carla revealed that communities reliably come together to recover from major shocks of external origin [28]. We hypothesize as follows.

Hypothesis $3 a$ (H3a): The pandemic leads to an increase in individual contributions to support public schools.

Prior research highlights the role of firm stakeholders in driving an organization's propensity to contribute to social causes including investors and employees [29]. On the one hand, an organizations' ability to facilitate resilience may be severely limited by the impact of the crisis, COVID-19 in our case, on their own resources [30]. On the other hand, engaging in CSR activities during the pandemic can increase the stock returns and stakeholder attention of firms. Prior research finds evidence of the positive effect of CSR on stock returns over a five-day period and possibly extending as long as 50 days [31]. If the firm counts goodwill among its assets, managerial utility maximization through post-disaster donations of some of the firms' wealth may be consistent with the wealth maximizing interest of the stockholders [28]. Along these lines, we hypothesize as follows.

Hypothesis $3 b(3 b)$ : The pandemic leads to an increase in institutional contributions to support public schools.

\section{Research Context and Data}

In our study, we collected data from the crowdfunding platform DonorsChoose.org, based in New York City, NY. It is a nonprofit organization established in 2000 that allows individuals and organizations to donate to public school classroom projects. Since launch, DonorsChoose helped public school teachers raise over a billion dollars with over 4 million unique donors benefiting more than 85,000 schools in the country ${ }^{3}$. The projects are initiated by

\footnotetext{
${ }^{3}$ Source: https://www.donorschoose.org/about/impact.html last accessed Nov 20, 2020
}

teachers who can request materials and resources for their classrooms. A typical project page might contain a description of the project, further information about the needs, the school, location, subject, grade level, how many students are impacted by this project, and how many donors have contributed to this project. On the platform, a regular campaign duration lasts about 120 days. We find that most successful projects are fully funded in about two months. If the donation reaches its target funding within the campaign period, DonorsChoose directly purchases the requested materials and sends them to the teacher. A project is considered partially funded if it does not reach its target within the campaign period. In this case, donors can choose to get their donations refunded as account credits to use towards other projects.

\subsection{Data}

We collected donation data from DonorsChoose.org via an API. The dataset contains donations from August 2019 to September 2020. In addition to the DonorsChoose.org data, we obtained data from Common Core of Data (CCD) of National Center for Education Statistics (NCES) about school demographics. CCD is the Department of Education's primary database on public elementary and secondary education in the US. It contains a comprehensive annual national database of all public elementary and secondary schools.

In the database, we have demographic information for schools as reported on the annual CCD School Universe Survey. The survey includes directory and status information, student membership disaggregated by grade, race/ethnicity and sex, and counts of students with free/ reduced-priced lunch plans. The demographic information we collected is for the 2019-2020 school year. We used the NCES school identifier to match the two databases. The final matched sample consists of 54,155 unique schools which cover $70 \%$ (54,155 out of $77,524)$ of US elementary and second schools.

\subsection{Variable Definitions}

We construct a set of variables specific to schools, and donors using the dataset described above.

3.2.1. Dependent Variables We use the logged amount of donations raised for each project as our main dependent variable [9]. We divide the main dependent variable into two additional component variables. The first is the amount raised from organizations and the second is the amount raised from individual donors. 
We use Funding Success: a binary variable indicating whether a project successfully raised its targeted total amount and Time to Success : the elapsed number of days before the project reached its funding goal as additional dependent variables for robustness tests. The latter measure could be especially critical in a pandemic where certain needs such as access to the internet or a computer become necessary for continuing education.

3.2.2. Key Independent Variable The main independent variable in our analysis is a binary measure, Stay-at-Home Order, representing the stay-at-home order of a state for a given project. We select this date as the critical measure because the stay-at-home order is the event with the most direct impact on schools and public education. We obtained these dates from Ballot Pedia ${ }^{4}$ for each state.

3.2.3. Control Variables Several other variables could potentially be associated with the total amount raised. First, we consider the project types that could influence the funding performance and operationalize project immediacy needs with two binary variables, Technology Needs Project ${ }^{5}$ and Basic Needs Project ${ }^{6}$. We also consider the usage of a word-of-mouth mechanism and use a binary variable Giving Page which is 1 for the projects raised through "Hand in Hand Giving Page" on the platform. Next, we account for the amount requested since this amount is highly related to donors' choice of projects they might wish to support. Also, it is intuitive that donors might feel more compelled to give to causes where a greater number of students can be reached through their donations. If given a choice between a project that is almost about to expire if unfunded (and thereby fail) and another that is going to remain open for funding for the near future, it is possible that donors might feel compelled to contribute to the former. To account for these explanations, we control for the amount requested (Amount Requested), the expected number of students impacted or reached by the donation (Num. Students Reached) and the total number of days a project is active (Time to Expire). Finally, we operationalize projects for low SES students with a binary variable School Poverty, which is 1 for the projects posted by a school whose proportion of students qualified for the free/reduced-price lunch plan is higher

\footnotetext{
${ }^{4}$ https://ballotpedia.org last accessed on Nov. 20, 2020

${ }^{5}$ Technology-based needs include "Virtual Trips", "Virtual Visitors", "Instructional Technology", and "Computers Tablets".

${ }^{6}$ Classroom basic needs include "Classroom Basics", "Flexible Seating", "Food", "Clothing Hygiene", "Books", "Reading Nooks", and "Desks Storage".
}

than the median cut.

The descriptive statistics for these variables of interest are shown in Table 1.

Table 1. Descriptive Statistics

\begin{tabular}{lllll}
\hline \hline Variable & & $\mathrm{N}$ & Mean & Std Dev \\
\hline Fund Amount Raised & $\$$ & 298597 & 427.56 & 761.44 \\
Fund from Organizations & $\$$ & 298597 & 282.12 & 646.91 \\
Fund from Individuals & $\$$ & 298597 & 145.03 & 356.45 \\
Amount Requested & $\$$ & 298597 & 655.53 & 1097.20 \\
Num. Students Reached & Count & 298597 & 103.23 & 168.76 \\
Time to Expire & Count & 298597 & 118.08 & 14.92 \\
Stay-at-Home Order & Binary & 298597 & 0.12 & 0.33 \\
School Poverty & Binary & 298597 & 0.55 & 0.50 \\
Technology Needs Project & Binary & 298597 & 0.23 & 0.42 \\
Basic Needs Project & Binary & 298597 & 0.48 & 0.50 \\
Giving Page & Binary & 298597 & 0.32 & 0.46 \\
Funding Success & Binary & 298597 & 0.73 & 0.44 \\
Time to Success & Count & 298597 & 55.21 & 50.21 \\
\hline \hline
\end{tabular}

\section{Empirical Analysis and Results}

State, territorial, tribal, and local governments have responded to the COVID-19 pandemic in the US with various declarations of emergency, closure of schools and public meeting places, lock-downs, and other restrictions intended to slow the progression of the virus. The temporal and geographic variation allow us to examine the causal effect of the pandemic on donor behavior, ruling out alternative explanations. We specifically leverage the date on which each state's stay-at-home order came into effect as an external shock to compare donation activity before and after the shock. In this section, we first present our before-after analysis at the project level to assess the impact of the COVID-19 pandemic on the donations raised through the platform. We then conduct analyses to examine how the impact of the pandemic varies across projects. Finally, we demonstrate the robustness of our results using alternative models and variable specifications.

\subsection{Model Specification and Main Results}

The econometric specifications are presented in Equation 1. The dependent variable is the log-transformed amount of donations raised for the project $i$. The main independent variable is a binary measure, $X$, indicating an issued stay-at-home order for the corresponding state for the project $i$. Moderating variables are included in the vector as $\bmod _{i}$, and $\alpha_{2, j}, j=1,2,3,4$ represent the regression coefficients for the direct effects of the moderating variables. We include the control variables $\left(\mathrm{Ctrls}_{i}\right)$ and take log transformations for all these controls variables. We include the school fixed effect to account for the heterogeneity across schools. We also include the fixed 
effects at the week level to adjust for temporal trends over our study period. We focus on the period from September 1st 2019 to June 1st 2020 for the baseline analysis to study the effect of the pandemic on donor behavior. We demonstrate our results are robust to a shorter or longer study period.

$$
Y_{i}=\beta_{1} X_{i}+\beta_{2} \text { Ctrls }_{i}+\text { Sch }_{i}+W_{i}+\epsilon_{i}
$$

The main results report in Table 2. We specify our regression models with heteroskedasticity-robust standard errors clustered around states. Model (1) in Table 2 presents results for the stay-at-home order on total amount raised to schools. The positive and significant coefficient $(\hat{\beta}=0.066, p<0.05)$ demonstrates that the funding amount increased by $6.6 \%$ after the stay-at-home order came into effect. This result shows evidence supporting H1a. We perform additional analyses to test the positive effect of the stay-at-home order indicator on crowdfunding outcomes and find it robust to alternative operationalizations (funding success and time to success), different study periods, and alternate aggregation level specifications. The results from Model (2)-(3) of Table 2 depict how funding amount changes after the event for schools with the higher or lower poverty level. The coefficients suggest that during the pandemic, the increase in the funding amount is higher if the project is posted by teachers of schools with more low income students. While the funding amount raised for the schools with greater share of low income students is lower before the pandemic, the donations for the poor and rich schools are on par with each other during the pandemic. These results provide evidence to support $\mathrm{H} 1 \mathrm{~b}$ by showing that as a response to the pandemic, there is a shift in online crowdfunded contributions towards projects from schools supporting lower SES students.

$\mathrm{H} 2$ states that communities prioritize high immediacy needs during the pandemic. Our empirical results show that technology-need based projects with the binary stay-at-home order variable has a positive and statistically significant coefficient $(\hat{\beta}=0.184, p<0.01)$. This implies that, as the stay-at-home order came into effect, technology-needs based projects began receiving $18.4 \%$ more funding compared to projects addressing other needs. In addition, we observe that the coefficient for the subsample of basic needs projects is not statistically significant, suggesting that the effect of stay-at-home order does not vary for those projects that address basic classroom needs. These results imply that $\mathrm{H} 2$ is supported.

In Model (6)-(7) of Table 2, we report results for Equation 1 where the dependent variables are the amounts raised from institutional donors and individual donors, respectively. While the coefficient estimate of the binary variable Stay-at-Home Order is not statistically significant in column (7), the estimate in column (6) is positive and significant. This suggests that after the state's stay-at-home order came into effect, organizations contributed more to school projects while no statistically-significant differences were observed among individual donors' contributions. These results imply that $\mathrm{H} 3 \mathrm{~b}$ is supported whereas $\mathrm{H} 3 \mathrm{a}$ is not supported.

This set of results provides the first evidence suggesting that the stay-at-home order during the pandemic is accompanied by better-off crowdfunding outcomes on the online platform. We find that the positive effect of the stay-at-home order is stronger for technology projects and for schools in poorer neighborhoods. We also observe that the stay-at-home order is associated with a noticeable increase in crowdfunding donation amounts contributed by organizational donors. Not only does the pandemic affect how much people give but also how donors distribute their donations. In Section 5, we discuss our findings further and offer theoretical explanations and implications for practice.

\subsection{Alternative Outcome Measures: Funding Success and Time to Complete}

Besides using Amount Raised as a dependent variable, we employ Funding Success as an alternative dependent measure to simulate the "all-or-nothing" funding model, where a teacher receives donations only if the raised amount equals or exceeds the target funding goal; otherwise, the project is considered unsuccessful, and the teacher does not receive any funds. Aligning with DonorsChoose's crowdfunding model, we measure Funding Success as a binary variable that indicates whether a project has total funding collected equal to the target funding goal. We set Funding Success to 1 if the project's collected funding is equal to or greater than its target funding goal; otherwise, Funding Success is zero. In our dataset, $73.7 \%$ projects are successful in obtaining funding. We also include Time to Success as another alternative dependent variable. We operationalize Time to Success as the number of days to reach the funding goal if a project was successfully funded, or total project duration if a project was not successfully funded. In our dataset, the average time to success of a successful project is 33 days. Earlier goal attainment also reduces the uncertainty of contributions from potential donors. With Funding Success and Time to Success as dependent variables, we specify the 
Table 2. Effects of Stay-at-Home Order on Donations

\begin{tabular}{|c|c|c|c|c|c|c|c|}
\hline & \multicolumn{7}{|c|}{ Dependent variable: } \\
\hline & \multicolumn{5}{|c|}{ Total Amount Raised } & \multirow{2}{*}{$\begin{array}{l}\text { Amount Raised } \\
\text { from Ind. } \\
(6) \\
\end{array}$} & \multirow{2}{*}{$\begin{array}{l}\text { Amount Raised } \\
\text { from Org. } \\
\text { (7) }\end{array}$} \\
\hline & $\begin{array}{l}\text { All } \\
\text { (1) }\end{array}$ & $\begin{array}{c}\text { Poverty }=1 \\
\text { (2) }\end{array}$ & $\begin{array}{c}\text { Poverty }=0 \\
\text { (3) }\end{array}$ & $\begin{array}{c}\text { Technology Proj. } \\
\text { (4) }\end{array}$ & $\begin{array}{c}\text { Basic Proj. } \\
\text { (5) }\end{array}$ & & \\
\hline Stay-at-Home Order & $\begin{array}{c}0.066^{* *} \\
(0.027)\end{array}$ & $\begin{array}{c}0.140^{* * *} \\
(0.038)\end{array}$ & $\begin{array}{l}-0.023 \\
(0.037)\end{array}$ & $\begin{array}{c}0.184^{* *} \\
(0.072)\end{array}$ & $\begin{array}{c}0.043 \\
(0.038)\end{array}$ & $\begin{array}{c}0.176^{* * *} \\
(0.048)\end{array}$ & $\begin{array}{l}-0.231 \\
(0.158)\end{array}$ \\
\hline \multicolumn{8}{|l|}{ Control Variables } \\
\hline School and Week (FE) & & $\checkmark$ & $\checkmark$ & $\checkmark$ & $\checkmark$ & $\checkmark$ & $\checkmark$ \\
\hline Observations & 298,597 & 164,466 & 134,131 & 68,858 & 144,541 & 298,597 & 298,597 \\
\hline $\mathrm{R}^{2}$ & 0.343 & 0.294 & 0.402 & 0.496 & 0.422 & 0.309 & 0.429 \\
\hline
\end{tabular}

Note: Robust standard errors are presented in the parentheses. ${ }^{* *} \mathrm{p}<0.05 ;{ }^{* * *} \mathrm{p}<0.01$

logistic model and Cox proportional hazards model, respectively. The regression results are consistent consistent when we employ the alternative dependent variables (as shown in Model (1)-(2) of Table 3).

\subsection{Validity of Before-After Analysis}

Our before-after analysis essentially creates a staggered difference-in-differences (DD) framework. Accordingly, we test the parallel trend assumption and confirm the validity of our main results by performing falsification tests. The relationship between crowdfunding performance and the stay-at-home order may be driven by unobserved factors confounded with funding trends. For instance, changes in macroeconomic conditions or the expansion of the crowdfunding platform in certain locations or schools could possibly affect the prevailing crowdfunding trends. Under such a possibility, crowdfunding performance might have already been increasing due to these alternative reasons and would continue to increase even without the presence of the pandemic. To account for the possibility of such pre-shock trends, we perform a time falsification check by including the measure - Num. Weeks to Policy, which represents the number of weeks to the stay-at-home order. A negative (or positive) value of Num. Weeks to Policy means that a project was launched before (or after) the stay-at-home order. ${ }^{7}$ From Model (3) of Table 3, we observe that the coefficient of the pre-period placebo variable is not statistically significant, suggesting that the parallel trends assumption is fulfilled and that the observed relationship between the funding amount and stay-at-home policy is unlikely to arise as a result of events that occur in periods prior to the policy.

The main analysis takes advantage of the timing of stay-at-home order which may differ across states

${ }^{7}$ For example, if the project commenced four weeks before the state order, then Num. Weeks to Policy is -4 ; if the project commenced four weeks after the state order, then Num. Weeks to Policy is 4. so that the econometric model could make use of the variations between schools who reside in states which already have stay-at-home order in effect and states that do not yet. One concern with this setting is that most states announced their stay-at-home orders closely next to each other in a few weeks during the late March to early April 2020. This is a relatively short time span compared to the study period (about one year) and hence the variation in "treatment" timing is limited. Moreover, donors in regions that do not have a stay-at-home order yet tend to be able to expect it will happen soon to their regions due to the huge amount of news coverage and the recognition that this will be a national emergency (i.e., there exists a "spillover effect"). To improve upon the causal identification of the study, we take advantage of more nuanced variations across geographical areas. In particular, different regions tend to have different political beliefs and that in turn will impact the perception of seriousness of the pandemic by their local residents. Hence, despite that different regions have stay-at-home order around the similar time period, people in different areas may have different viewpoints on how long it will last and how long schools will be closed. Along with these lines, we use the presidential election results by state as a proxy of donors' consciousness and include a binary variable Blue States interacting with the stay-at-home order. The significant and positive coefficient of the interaction term (shown in column (4) of Table 3) suggests that regions with higher consciousness of the seriousness of the pandemic experience stronger effects on the funding performance, providing fine-grained evidence to support our main finding.

\subsection{Other Robustness Checks}

We perform robustness checks using different time periods. First, we focus on a short time period from Feb 1, 2020 to Jun 1, 2020 to avoid potential bias driven by other events that might occur in the vicinity of the 
Table 3. Model Validity and Additional Analyses

\begin{tabular}{|c|c|c|c|c|c|c|c|}
\hline & \multicolumn{7}{|c|}{ Dependent variable: } \\
\hline & \multirow{2}{*}{$\begin{array}{c}\text { Funding Success } \\
\text { Logistic Model } \\
\text { (1) }\end{array}$} & \multirow{2}{*}{$\begin{array}{c}\text { Time to Success } \\
\text { Cox Model } \\
\text { (2) }\end{array}$} & \multicolumn{5}{|c|}{ Amount Raised } \\
\hline & & & $\begin{array}{c}\text { Pre Period } \\
\text { (3) }\end{array}$ & $\begin{array}{l}\text { DDD } \\
(4)\end{array}$ & $\begin{array}{c}\text { Short Period } \\
\text { (5) }\end{array}$ & $\begin{array}{c}\text { Long Period } \\
\text { (6) }\end{array}$ & $\begin{array}{c}\text { School Leve } \\
\text { (7) }\end{array}$ \\
\hline Num. Weeks to Policy & & & $\begin{array}{c}0.0004 \\
(0.0003)\end{array}$ & & & & \\
\hline Stay-at-Home Order & $\begin{array}{c}0.184^{* * *} \\
(0.058)\end{array}$ & $\begin{array}{c}0.129^{* * *} \\
(0.028)\end{array}$ & & $\begin{array}{c}0.012 \\
(0.027)\end{array}$ & $\begin{array}{c}0.068^{* * *} \\
(0.025)\end{array}$ & $\begin{array}{c}0.023^{* * *} \\
(0.010)\end{array}$ & $\begin{array}{c}0.037^{* * *} \\
(0.014)\end{array}$ \\
\hline $\begin{array}{l}\text { Stay-at-Home Order } \\
\times \text { Blue States }\end{array}$ & & & & $\begin{array}{c}0.097^{* * *} \\
(0.012)\end{array}$ & & & \\
\hline Control Variables & & & & $\checkmark$ & $\checkmark$ & $\checkmark$ & $\checkmark$ \\
\hline School and Week (FE) & $\checkmark$ & $\checkmark$ & $\checkmark$ & $\checkmark$ & $\checkmark$ & $\checkmark$ & $\checkmark$ \\
\hline Observations & 298,597 & 298,597 & 298,597 & 82,708 & 82,708 & 389,816 & 267,727 \\
\hline $\mathrm{R}^{2}$ & 0.343 & 0.294 & 0.402 & 0.496 & 0.422 & 0.309 & 0.429 \\
\hline
\end{tabular}

time window and to ensure that the exogenous shock happens in the middle of the period. Second, we use a longer time range from Aug 1, 2019 to Oct 1, 2020 to study the long-term effect of the stay-at-home order extending to the reopening period of schools during the fall semester. We observe consistent results, providing further evidence to support H1a and show that the funding amounts increase during the pandemic.

In addition, we aggregate the data to the school level by averaging all key variables for a school per project. We repeat the before-after analysis to examine the effect of COVID-19 pandemic on overall donations per project at the school level. This school-level analysis allows us to draw additional insights. Schools that repeatedly initiate projects on the crowdfunding platform might develop a reputation in the community and either attract or repel donors to a greater extent than normal (e.g., repeated visibility on the platform might lead to a school being viewed as one in constant need of funds). The consistent results reported in column (7) of Table 3 suggest that our main findings still hold at the school-aggregation level.

\section{Discussion}

With increasing evidence of teachers going above and beyond their typical responsibilities to help educate children during the pandemic, we observe a voluntary donor-supported platform DonorsChoose, and its affiliated community members rally to support education. Our analyses find that as a response to the pandemic's exogenous shock and the ensuing stay-at-home orders across states, there was an increase in the donations schools received through the DonorsChoose platform. A straightforward interpretation of this result could be that it supports the complementariness view [17] of voluntary giving.
If the needs of different public schools are unlikely to be directly addressed by the government or remain underfunded at the current rate of government apportioned funding for schools, we observe a share of the burden being borne by the community through greater overall contributions observed on the platform.

Disaster Response The online crowdfunding community exhibits an adaptive form of resilience by addressing needs in unique ways. We find that, prior to the pandemic, the donor community perceived projects requesting technology-related help as lower in priority. Technology projects received a lower amount of funding compared to other types of projects being posted by teachers. However, the interaction effects observed in our results suggest that, as the stay-at-home order went into effect, technology-needs based projects began receiving more funding compared to projects pertaining to other needs of students. The pandemic put technological needs front and center and the donor community quickly adapted to this change. A theoretical explanation for this finding could be the immediacy bias, noted earlier, when making judgments and decisions about humanitarian aid, especially to humanitarian crises that happen to arouse immediate emotion [27]. The donor community might have perceived a tangible need for additional laptops or computers that they observed through interaction with children at home, through neighbors, or family members. Such needs are also easier for the teachers to justify on the platform through project descriptions and project tags, as the pandemic caused tangible and explicit disruptions to the public.

We observe an ability in the platform for the community to come together and help children in need. First, our analysis reveals that projects addressing 
basic student needs (such as textbooks, reference books, and basic supplies) receive a higher amount of funding when compared to projects addressing other needs. Second, our results reveal an objective increase in funding received across projects posted by schools which had significant numbers of low income students. The crowdfunding platform clearly posts information about the poverty level of students in the corresponding school and precisely details how funds raised for the project will be spent by the school. When considered together, these findings suggest that the crowdfunding community recognizes needs (e.g., children being sent home from school; students from low socio-economic status (SES) communities being affected; lived experiences of families facilitating distance learning) and responds positively through contributions on their chosen crowdfunding platform. This form of resilience is especially important since schools and school districts with higher proportions of students with low socio-economic status have fewer resources to begin with and resource shortages are highly likely to be exacerbated during the pandemic.

Pandemic Response: Individuals vs. Organizations Individual and institutional philanthropy each have their participation drivers. Our results show nuanced ways in which contributions to the platform differ during the pandemic, depending on the entity driving the donation. After the state's stay-at-home order came into effect, we observe that organizational donors contribute more in response, while individual donors' donation amounts did not change significantly. As posited earlier, the latter finding could be attributed to challenging economic conditions impacting individuals more adversely.

Limitations and Future Work Despite our performing of numerous robustness checks (including examination of alternate outcome measures) and ruling out other possible explanations, there remain certain limitations in our analyses. While our setting allows for a quasi-experimental setup and a difference-in-differences framework to be applied to tease out the effect of the exogenous shock (the stay-at-home order), we are unable to apply true experimental treatments and observe actual responses due to the archival data analysis methods we employ. With the current setting, there are the potential confounders to their effect on crowdfunding outcomes. For example, many nation-wide and local policies (e.g., social distancing, public school funding, tax relief, etc) ensued from the pandemic and might impact residents' spending and donation decisions. In addition, the wording of project descriptions could evolve during the pandemic and influence donation behavior. More analyses with fine-grained the pandemic spread data can be conducted to strengthen our causal inferences.

There are several other questions that worth exploring further to augment our study. It would be interesting and insightful to look into the relative roles between existing contributors and new contributors on the platform. For instance, how are the donations for a project distributed between existing contributors and new contributors (those only come and join the platform after the pandemic)? Does the donation amount from existing contributors increase from their own baseline before the pandemic? Do new contributors play a significant role in supporting new school education projects and what is their focus? Those questions can help platforms (more broadly decision-makers) decide where to invest their resources and efforts in attracting public attention. We plan to collect donor-level information for each project to dig into these questions.

Despite these limitations, our study has important implications for public schools and the role of platforms. Individual and institutional donors exhibit varied reactions to differently attuned calls to action (e.g., basic versus technology needs) and must be separately considered when attracting donors to a project. Teachers and platform liaisons should pay specific attention to the overall message and salience of factors like vulnerable sub-populations, timeliness of needs, and the number of students their project outcomes serve in their promotional marketing and messages when seeking funds. Despite the best of intentions, sometimes, it is the most vulnerable students and poorest schools districts that might suffer most during global crises. Among other results, our study's heartening finding is that donors in crowdfunding platforms seem to sense acute as well as wide-ranging impacts of external shocks, and perform a critical service in building community resilience.

\section{References}

[1] K. Brantley-Jones, "Digital divide amplified: Schools scramble to provide at-home learning options," $A B C$ News, 2020.

[2] A. Ujifusa, "Schools get 13.5 billion usdin coronavirus package signed into law," Education Week, 2020.

[3] L. Partelow, J. Yin, and S. Sargrad, "Why k-12 education needs more federal stimulus funding," Center for American Progress, 2020.

[4] J. Smialek, B. Casselman, and G. Friedman, "Workers face permanent job losses as the virus persists," The New York Times, 2020.

[5] A. W. Bartik, M. Bertrand, Z. Cullen, E. L. Glaeser, 
M. Luca, and C. Stanton, "The impact of covid-19 on small business outcomes and expectations," Proceedings of the National Academy of Sciences, vol. 117, no. 30, pp. 17656-17666, 2020.

[6] G. Burtch, A. Ghose, and S. Wattal, "Cultural differences and geography as determinants of online prosocial lending," MIS Quarterly, vol. 38, no. 3, pp. 773-794, 2014.

[7] G. Burtch and J. Chan, "Investigating the relationship between medical crowdfunding and personal bankruptcy in the united states: Evidence of a digital divide," MIS Quarterly, vol. 43, no. 1, pp. 237-262, 2019.

[8] H. Geva, O. Barzilay, and G. Oestreicher-Singer, "A potato salad with a lemon twist: Using a supply-side shock to study the impact of opportunistic behavior on crowdfunding platforms," MIS Quarterly, vol. 43, no. 4, pp. 1227-1248, 2019.

[9] P. Younkin and V. Kuppuswamy, "The colorblind crowd? founder race and performance in crowdfunding,' Management Science, vol. 64, no. 7, pp. 3269-3287, 2018.

[10] G. Burtch, A. Ghose, and S. Wattal, "The hidden cost of accommodating crowdfunder privacy preferences: A randomized field experiment," Management Science, vol. 61, no. 5, pp. 949-962, 2015.

[11] Y. Hong, Y. Hu, and G. Burtch, "Embeddedness, pro-sociality, and social influence: Evidence from online crowdfunding," MIS Quarterly, vol. 42, no. 4, pp. 1211-1224, 2018.

[12] K. Kim and S. Viswanathan, “The'experts' in the crowd: The role of experienced investors in a crowdfunding market," MIS Quarterly, vol. 43, no. 2, pp. 347-372, 2019.

[13] C. L. Exley, "Using charity performance metrics as an excuse not to give," Management Science, vol. 66, no. 2, pp. 553-563, 2020.

[14] G. Oestreicher-Singer and A. Sundararajan, "Recommendation networks and the long tail of electronic commerce," Mis quarterly, pp. 65-83, 2012.

[15] P. Frumkin, Strategic giving: The art and science of philanthropy. University of Chicago Press, 2008.

[16] P. Dekker and L. Halman, The values of volunteering: Cross-cultural perspectives. Springer Science \& Business Media, 2003.

[17] L. Dahlberg, "Interaction between voluntary and statutory social service provision in sweden: a matter of welfare pluralism, substitution or complementarity?," Social Policy \& Administration, vol. 39, no. 7 , pp. 740-763, 2005.

[18] I. Stadelmann-Steffen, "Social volunteering in welfare states: Where crowding out should occur," Political Studies, vol. 59, no. 1, pp. 135-155, 2011.

[19] K. Bales, "Measuring the propensity to volunteer," Social Policy \& Administration, vol. 30, no. 3, pp. 206-226, 1996.

[20] F. H. Norris, J. D. Foster, and D. L. Weisshaar, "The epidemiology of gender differences in ptsd across developmental, societal, and research contexts.," 2002.

[21] B. L. Burke, A. Martens, and E. H. Faucher, "Two decades of terror management theory: A meta-analysis of mortality salience research," Personality and Social Psychology Review, vol. 14, no. 2, pp. 155-195, 2010.
[22] M. B. Salzman, "Globalization, culture, and anxiety: Perspectives and predictions from terror management theory," Journal of Social Distress and the Homeless, vol. 10, no. 4, pp. 337-352, 2001.

[23] S. Hallegatte, A. Vogt-Schilb, M. Bangalore, and J. Rozenberg, Unbreakable: building the resilience of the poor in the face of natural disasters. World Bank Publications, 2016.

[24] B. Herold, "The disparities in remote learning under coronavirus (in charts)," Education Week. https://www. edweek. org/ew/articles/2020/04/10/the-disparities-in-remote-learning-under-corona html, 2020.

[25] D. Fetherstonhaugh, P. Slovic, S. Johnson, and J. Friedrich, "Insensitivity to the value of human life: A study of psychophysical numbing," Journal of Risk and uncertainty, vol. 14, no. 3, pp. 283-300, 1997.

[26] M. Huber, L. Van Boven, A. P. McGraw, and L. Johnson-Graham, "Whom to help? immediacy bias in judgments and decisions about humanitarian aid," Organizational Behavior and Human Decision Processes, vol. 115, no. 2, pp. 283-293, 2011.

[27] L. Van Boven, K. White, and M. Huber, "Immediacy bias in emotion perception: Current emotions seem more intense than previous emotions.", Journal of Experimental Psychology: General, vol. 138, no. 3, p. 368, 2009.

[28] C. M. Douty, "Disasters and charity: some aspects of cooperative economic behavior," The American Economic Review, vol. 62, no. 4, pp. 580-590, 1972.

[29] A. Dyck, K. V. Lins, L. Roth, and H. F. Wagner, "Do institutional investors drive corporate social responsibility? international evidence," Journal of Financial Economics, vol. 131, no. 3, pp. 693-714, 2019.

[30] C. S. Marcum, C. A. Bevc, and C. T. Butts, "Mechanisms of control in emergent interorganizational networks," Policy Studies Journal, vol. 40, no. 3, pp. 516-546, 2012.

[31] S. C. Qiu, J. Jiang, X. Liu, M.-H. Chen, and X. Yuan, "Can corporate social responsibility protect firm value during the covid-19 pandemic?," International Journal of Hospitality Management, p. 102759, 2020. 